\title{
O sinal da Cruz em um catecismo na língua geral da Amazônia [175-]
}

The sign of the Cross in a catechism in the general language of the Amazon [175-]

\author{
Ruth Monserrat*, Cândida Barros ${ }^{* *}$, Karl Heinz Arenz \& Gabriel Prudente ${ }^{* * *}$ \\ DOI: http://dx.doi.org/10.31057/2314.3908.v6.n2.22960
}

Resumo: O objetivo do trabalho é apresentar uma transcrição do primeiro capítulo de um catecismo manuscrito anônimo em língua geral e parcialmente em latim, produzido, com muita probabilidade, por um dos jesuítas de língua alemã que atuaram na Amazônia em meados do século XVIII. O capítulo trata sobre os temas do nome do "cristão" e da prática do sinal da cruz. A transcrição é acompanhada de notas com as traduções para o português, sendo precedida por um texto de apresentação com hipóteses acerca da autoria do catecismo, o contexto histórico da produção do documento e a situação linguística das missões do Grão-Pará no setecentos.

Palavras-chave: Catecismo; Língua Geral; Jesuítas; Amazônia portuguesa; Século XVIII.

Abstract: The aim here is to present a transcription of the first chapter of an anonymous manuscript catechism in both Língua Geral and, partially, in Latin, which was very probably composed by one of the German-speaking Jesuits that worked in the Amazon

\footnotetext{
*Universidade Federal do Rio de Janeiro. E-mail: ruth.monserrat@gmail.com

** Museu Paraense Emílio Goeldi. E-mail: mcandida.barros@ gmail.com

*** Universidade Federal do Pará. E-mail: karlarenz@ufpa.br y gabrielprudente1@yahoo.com.br
}

120 Monserrat, Barros, Arenz \& Prudente. O sinal da Cruz em um catecismo na língua... 120-141. 
region in the mid-18th century. This chapter deals with the matters of the name "Christian" and the practice of the sign of the cross. The transcription is accompanied by notes on the translation into Portuguese, and is prefaced by the presentation of hypotheses concerning the author of the catechism, the historical context of its production, and the linguistic situation of the missions of Grão-Pará in the 1700s.

Keywords: Catechism; Língua Geral; Jesuits; Portuguese Amazon; 18th century.

Recibido: 27 de enero de 2017.

Evaluado: 4 de marzo de 2018. 
O manuscrito Doutrina christaã em lingoa geral dos Indios do Estado do Brasil e Maranhaõ, composta pelo P. Philippe Bettendorff, traduzida em lingoa geral $e$ irregular, e vulgar uzada nesses tempos (Fol. 1- 6, ms.1089, Biblioteca da Universidade de Coimbra) ${ }^{1}$ (doravante Doutrina) é anônimo e sem data. A caligrafia do códice oferece algumas pistas sobre a identidade de seu autor. A forma de grafar o sinal de parênteses $(/:: /)^{2}$, revela que o autor dominava a língua alemã (Monserrat, Barros\&Schmidt-Riese, 2017).

A hipótese a respeito do códice é que ele foi provavelmente escrito por um dos oito jesuítas centro-europeus de língua alemã que chegaram à Amazônia entre 1750 e 1753 para atuar como missionários. Esse grupo deixou testemunhos do seu processo de aprendizado da língua geral. Além da Doutrina, escreveram três dicionários (Prudente, 2017) e um extrato gramatical (Rosa, 1994) sobre a língua geral (Barros \& Monserrat, 2016):

Quadro 1:Textos em língua geral escritos pelos jesuítas centro-europeus.

\section{Doutrina christaã em lingoa geral dos Indios do Estado do Brasil e Maranhã̃}

[pertencente à Biblioteca da Universidade de Coimbra, ms. 1089] (Anônimo, 175- a)

"Prosodia da lingoa" [dos Indios] [pertencente à Biblioteca da Academia de Ciências de Lisboa, fol. 2r. - 85v.]. (Anônimo, 175- b)

Vocabulário da língua do Brazil [pertencente à Biblioteca Nacional de Lisboa, códice 3143, fol. 2r. 172r.] (Anônimo, 175- c)

Dicionário Português-Língua Geral e Língua Geral-Português [pertencente à Biblioteca Municipal de Trier, ms. 1136/2048 4º fol. 1r-65v] (Anônimo,1756)

Specimen da língua brasílica vulgaris, Anselm Eckart (Eckart, 1778)

Todas as fontes acima assinalam que a língua geral usada então nas missões não correspondia mais àquela que os missionários tinham aprendido nos catecismos e nas gramáticas jesuíticas impressas (Anchieta, 1595; Figueira, [1621] 1687; Araújo, 1618; Araújo \& Leam 1687). O padre alemão Anselmo Eckart (um dos candidatos a autor do catecismo parcialmente transcrito adiante) identificava as missões "paraenses" como o espaço da língua geral "corrompida", diferente do modo de falar dos índios tupinambá, associado ao Estado do Brasil:

Deus non moritur, Tupànomanói. este é genuíno modo de falar no Brasil o dialeto Toupinambeus (sic). Mas nas Missões Paraenses, onde o idioma já está um tanto quanto corrompido, assim dizem: Deus, Tupã, ou Tupána, non, nitiú, moritur, omanó" (Eckart, 1778 apud 1994,p. 177) [negrito acrescentado ao original]

\footnotetext{
${ }^{1} \mathrm{O}$ manuscrito tem 125 fólios, frente e verso, organizado em seis livros e 78 capítulos

${ }^{2}$ Uso dos sinais de parênteses nos enunciados [1.P, 3.R e 27.R].

122 Monserrat, Barros, Arenz \& Prudente. O sinal da Cruz em um catecismo na língua... 120-141.
} 
Foi esse uso da negação atribuído às missões - nitiú, mencionado acima por Eckart (1778), que o autor da Doutrina usou no capítulo aqui transcrito ${ }^{3}$. Em passagem de outro capítulo ele emprega a mesma expressão "nitiú omanó" ['ele não morreu'], empregada por Eckart em 1778.

R. Nitiúomanójebýráma ??:opŷatãpupéojeupir.

Nitiú omano jebyr aráma 'não morrerá de novo’ o-pyatãpupé o-jeupír 'com a própria força se elevou'. (Capítulo sobre a ascensão de Cristo ao céu). [trad. R.M.]

Ascendit immortalis, propriâ virtuteElevatus. (Anônimo 175-a, f.30r) [negrito acrescentado ao original]

As cinco fontes linguísticas escritas pelos jesuítas de língua alemã do período entre 1750 e 1759 fazem uso do termo "vulgar" para se referir ao modo de falar a língua geral dos índios das missões naquele momento ("nesses tempos", como diz a Doutrina), em oposição à forma registrada nas obras impressas em tupi no século XVII. É esse registro "vulgar" da língua geral que o autor de Doutrinas e propõe a usar para adequar o diálogo de pergunta e resposta jesuítico tradicional (associado a "Bettendorff") a uma audiência que não mais dominava o registro jesuítico impresso do tupi.

As missões paraenses foram espaços de mudança da língua geral devido à intensa mobilidade e diversidade etnolinguística de sua população. Alguns jesuítas do século XVIII mencionam que as missões não eram mais ocupadas por índios descidos que falavam a língua geral (Daniel, 2004, p. 334). Ao chegarem às missões, os índios eram socializados no seu cotidiano pela variedade da língua geral "corrompida"do século XVIII, segundo o padre João Daniel (2004, p. 334). A circulação dessa variedade por outros setores coloniais se deu devido à mobilidade de homens e mulheres das missões por conta das redes de trabalho compulsório às quais estavam obrigados. Algumas mulheres eram mandadas para as casas dos colonos como amas de leite ou como farinheiras. A parte masculina das missões passava ao menos seis meses do ano como remeira, período em que os homens ficavam fora da missão e em contato com outros índios. A regulamentação do trabalho dos índios da missão estava definida pelo "Regimento das missões" de 1686 (Mattos, 2012).

Levando em consideração as marcas germânicas da escrita do documento e o registro da língua geral empregado como próprio do século XVIII, podemos considerar que a Doutrina faz parte de um corpus documental produzido pelos oito jesuítas centroeuropeus de língua alemã que atuaram no Estado do Grão-Pará e Maranhão entre 1750 e 1757.

A vinda deste grupo para a Amazônia portuguesa foi articulada pelo padre austríaco Roque Hundertpfundt (1709-1777), que atuava na região desde a década de 1750. Hundertpfundt era muito próximo da então rainha de Portugal Maria Ana de Áustria. A consorte real requereu junto ao superior geral da Companhia de Jesus, o padre Francisco Retz, que este autorizasse o envio de missionários de língua alemã para o Grão-Pará e Maranhão, conforme o pedido do padre Roque, que havia sido chamado à corte em 1749 na qualidade de procurador da Vice-Província do Maranhão.

\footnotetext{
${ }^{3}$ Uso de nitio: ver enunciados [3 R, 4 P, 4 R, 13 P, 31 R].
}

123 Monserrat, Barros, Arenz \& Prudente. O sinal da Cruz em um catecismo na língua... 120-141. 
Em 1750, foram enviados à Amazônia lusa dois padres, Lourenço Kaulen (1716c.1797) e Antônio Meisterburg (1719-1799). Em 1753 chegaram à região os padres Martinho Schwartz (1718-1788), Anselmo Eckart (1721-1809), David Fay (1722-1767), Henrique Hoffmayer (1721-1757), João Nepomuceno Szluha (1723-1803) e José Kayling (1725-1791). No momento em que foram convocados, estes padres eram docentes em diferentes colégios jesuíticos localizados no Sacro Império Romano Germânico, portanto o trabalho nas aldeias do Grão-Pará e Maranhão foi sua primeira e única experiência como missionários (Leite, 1949a, 1949b; Meier \& Aymoré, 2005).

Segundo o relato do padre Anselmo Eckart, o plano inicial do padre Hundertpfundt contemplava a vinda de doze missionários, mas apenas os oito citados foram enviados (Eckart apud Papavero \& Porro, 2013, p. 63). Uma possível explicação para a interrupção do envio de mais padres centro-europeus para a Amazônia foi o falecimento da rainha de Portugal Maria Ana de Áustria em 1654, visto que ela foi a intermediária entre o padre Hundertpfundt e o superior geral dos jesuítas, o padre Francisco Retz, como supracitado. A morte da rainha acabou por fortalecer ainda mais o poder do secretário régio Sebastião José de Carvalho e Melo -que posteriormente recebeu o título com o qual ficou mais conhecido na história-, o Marquês de Pombal.

Em meados do século XVIII Carvalho e Melo assumiu a secretaria de Estado de Portugal. Este político esteve à frente do governo luso entre 1750 e 1777, instituindo políticas que objetivavam modernizar o Estado português através da promoção de reformas econômicas, políticas e educacionais (Maxwell, 1996). O estado do Grão-Pará e Maranhão era uma região estratégica para o plano pombalino de recuperação econômica do império luso. Não por acaso Carvalho e Melo enviou seu irmão Francisco Xavier de Mendonça Furtado para o governo do norte da América portuguesa.

Durante o governo pombalino, ocorreram mudanças na relação entre Portugal e os membros da Companhia de Jesus. Adepto do regalismo, Carvalho e Melo passou a ver com maus olhos os negócios e a interferência dos inacianos no império luso, em especial no Grão-Pará e Maranhão, de onde recebia missivas de seu irmão governador sobre as contendas dos jesuítas com os colonos da região, principalmente sobre a questão do uso da mão de obra indígena.

Foi neste contexto, no início da década de 1750, que chegaram ao Estado do Grão-Pará e Maranhão os oito jesuítas da Europa Central supracitados. Eles permaneceram menos de dez anos na Amazônia, mas produziram diversos documentos de caráter linguístico (dicionários e catecismo em língua geral), bem como relatos de suas experiências na região amazônica (Eckart apud Papavero \& Porro, 2013).Parte desse grupo atuou na região do rio Xingu e do rio Madeira, e outra, no Maranhão. Eles eram chamados de "tapuitinga" ("bárbaro branco", em tupi) pelos índios das missões amazônicas, segundo o padre David Fay (Fay apud Ronai, 1942, pp. 268-269).

Em um momento de redefinição das fronteiras coloniais ultramarinas entre Portugal e Espanha em virtude do Tratado de Madri (1750), a presença dos jesuítas centro-europeus em áreas fronteiriças na Amazônia foi vista com desconfiança pelas autoridades coloniais. Em virtude disso, os "tapuitinga" sofreram diversas acusações de conspiração com colonos e índios e de desobediência às leis régias. Não é de estranhar, assim, que estejam entre os primeiros jesuítas perseguidos e expulsos do Grão-Pará e Maranhão, sendo encarcerados em Portugal, alguns deles por quase vinte anos, até o fim do governo do Marquês de Pombal em 1777 (Prudente, 2017, pp. 80-125; Fernández Arrillaga \& García Arenas, 2009, pp. 227-256). 
A expulsão dos jesuítas dos territórios ultramarinos de Portugal foi o pontapé inicial na campanha anti-jesuítica da Europa, que culminou com a supressão da Companhia de Jesus (Wright, 2006, pp. 178-214). Antes disso, as resoluções pombalinas cada vez mais desfavoreciam os interesses da Ordem, sobretudo a partir de 1755, "o ano da virada na Amazônia portuguesa", nas palavras de Francisco Jorge dos Santos e Patrícia Maria Melo Sampaio (Santos \& Sampaio, 2008). Entre as diversas medidas que provocaram uma inflexão na política colonizadora lusa, constou a perda do poder temporal pelos padres regulares (franciscanos, carmelitas, mercedários e jesuítas) sobre os índios amazônicos e a secularização das missões, transformadas em vilas.

As resoluções de Pombal seriam aglutinadas e ampliadas no documento do Diretório dos índios (Portugal, 1758), que previa em seu sexto parágrafo a proibição do uso da língua geral ou de outras línguas nativas no trato com os índios e a promoção da língua portuguesa. A questão do uso da língua geral na Amazônia já era discutida entre Mendonça Furtado e Pombal, como é possível observar em algumas cartas trocadas entre os dois (Mendonça, 2005).

Furtado via o difundido uso do tupi no Grão-Pará e Maranhão como obstáculo às novas diretrizes lusas para a região. No entanto, mesmo em um contexto político desfavorável ao uso da língua geral na Amazônia, os jesuítas continuaram a produzir documentos de caráter linguístico e religioso utilizando o tupi, como dicionários e catecismos (Prudente, 2017). Dessa forma, os jesuítas não abriram mão de seu modus operandi que, seguindo o princípio apostólico da acommodatio, previa a utilização das línguas dos nativos dos locais de missão para evangelizá-los. Nesse sentido, a Doutrina, tendo sido escrita na época pombalina, é um exemplo da persistência dos jesuítas na região amazônica em utilizar uma língua indígena para a catequese, contrariando frontalmente as ordens metropolitanas.

Transcrevemos abaixo o capítulo "Sobre o fim da criaçaõ, sinal da cruz e meyos da salvaçaõ" (fólios 1 - 6). São 36 perguntas e respostas sobre os temas do significado de "cristão" e da prática do sinal da cruz (Barros e Monsserrat 2016), organizados em duas colunas, uma em língua geral e outra parcialmente em latim. O uso do latim como língua de tradução nos documentos produzidos pelos padres centro-europeus evidencia a sólida formação desses religiosos naquele idioma, além de ser uma estratégia para que outros missionários sem domínio do português pudessem compreender o sentido dos termos em língua geral, como no caso da Doutrina.

A transcrição paleográfica é semi-diplomática. Na medida do possível, foram preservadas e reproduzidas as rasuras presentes no documento, bem como a grafia das duas colunas. Houve expansão de algumas das abreviaturas por meio de itálicos, outras vezes por colchetes. As interferências foram introduzidas também por colchetes. A numeração dos turnos de perguntas e respostas foi acrescentada pelos editores. Procurou-se manter a mesma disposição dos enunciados nas duas colunas do original, pois uma hipótese é que seu autor tenha querido estabelecer uma correspondência interlínguas organizada espacialmente. Não foi possível, porém, seguir esse procedimento quando houve expansão de abreviaturas ou acréscimos em colchetes.

A transcrição é acompanhada de notas de rodapé contendo as traduções para o português do texto em língua geral (feitas por Ruth Monserrat) e do texto em latim (feitas por Ilario Govoni e Karl Arenz). A tradução da língua geral para o português manteve as glosas instituídas nas fontes tupi jesuíticas. Por exemplo, a palavra tecoangaipaba (ver 34.R) é traduzida por 'pecado', como fixou-se nos catecismos e 
dicionários jesuíticos, e não por 'maldade' ou por'ação má' ou 'vida má', como ficaria pela sua morfologia: tecó-áng.aíb-aba.

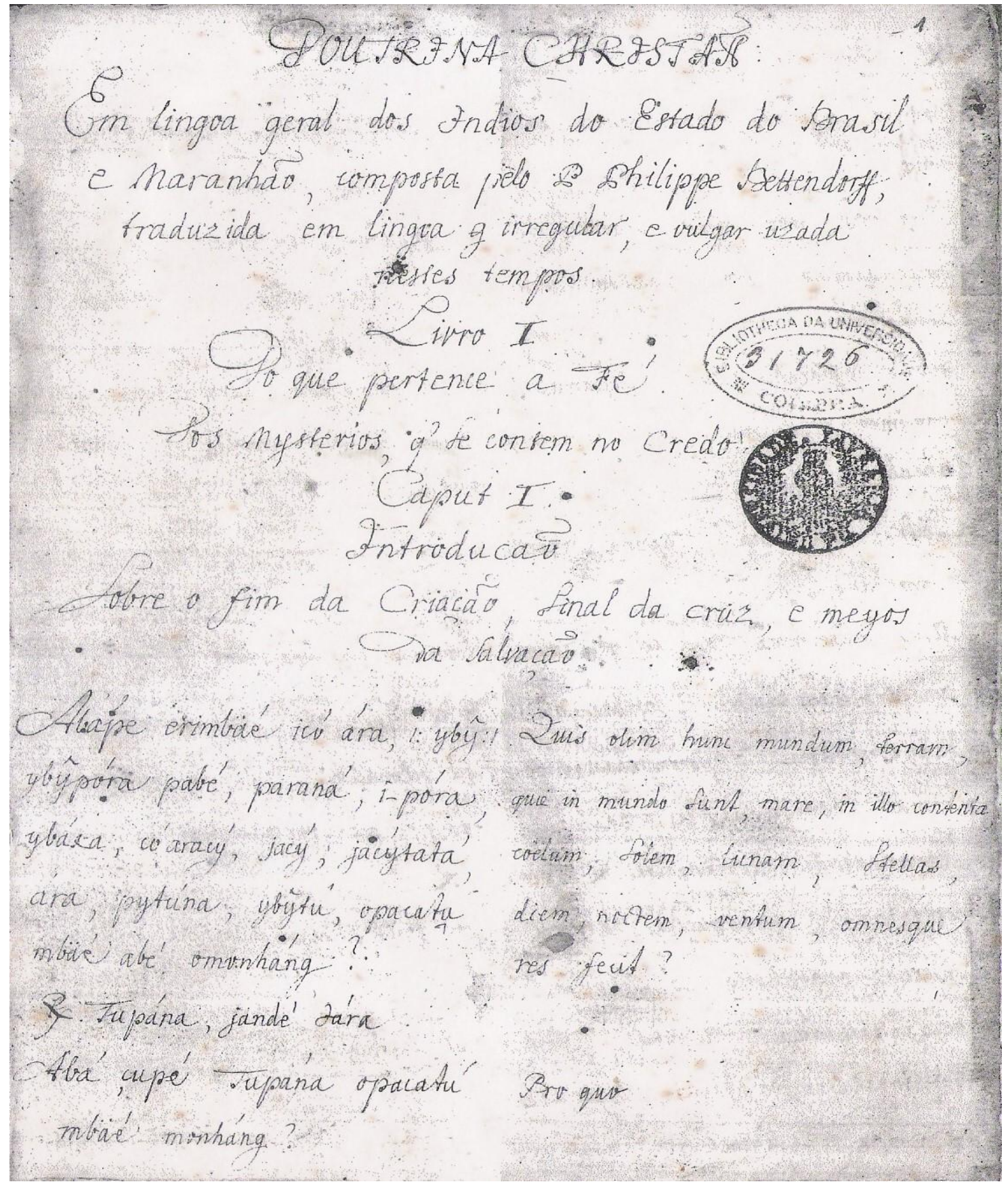

Imagem 1: Primeiro fólio da Doutrina Christã Em lingoa geral dos Indios do Estado do Brasil e Maranhão, com um carimbo da Biblioteca da Universidade de Coimbra. 


\section{DOUTRINA CHRISTÃ̃ \\ Em lingoa geral dos Indios do Estado do Brasil \\ e Maranhaõ, composta pelo P. Philippe Bettendorff, traduzida em lingoa g irregular, e vulgar uzada \\ nesses tempos \\ Livro I \\ Do que pertence a Fé \\ Dos mysterios, q' se contem no Credo \\ Caput I \\ Introduçaõ \\ Sobre o fim da Criaçaõ, Sinal da cruz, e meyos \\ da Salvaçaõ}

[Fl. 1]

1. P.Abápe erimbäé icó ára, /: ybŷ :/

ybŷpóra pabé, paraná; i-póra, ybáka, có aracý, jacý; jacýtatá, ára, pytúna, ybŷtu, opacatu

mbäé abé omonháng? ${ }^{4}$

1. R. Tupána, jandé Iára. ${ }^{6}$

2. P. Abá çupé Tupána opacatú mbäé monháng?

$$
[\mathrm{Fl} .1 \mathrm{v}]
$$

2. R. Jandébo, jandé mbäérama, çöó etá, jandé rembaberáma amó, amó jandé rembiuaráma.

Pirá recé jabé jebŷr: cóaracý omëengaráma ára jandébo: jacý, cendyráma, pytúnarame: jabé jebŷr opacatú amó, Tupána remimonhanga recé jandé mbäeráma nhénhé: ${ }^{9}$
[Fl.1]

Quis olim hunc mundum, terram, quæ in mundo sunt, mare, in illo contenta cœlum, solem, lunam, stellas, diem, noctem, ventum, omnes quæ res fecit? ${ }^{5}$

Pro quo ${ }^{8}$

$$
\text { [Fl. 1v] }
$$

animalia, alia ut educemus, alia, que comedamus.

De piscibus idem est: solem, ut det diem nobis : lunam, ut luceat, cum fuerit nox : idem est de omni alio, quod Deus fecit in usum nostrum denique. $^{10}$

\footnotetext{
${ }^{4}$ Tupi: "[P.] Quem antigamente este mundo, /: a terra:/ e todos os habitantes da terra, os rios; seus habitantes,

o céu, o sol, a lua; as estrelas, o dia, a noite, o vento, todas as coisas também criou?"

${ }^{5}$ Latim: "R. Quem é que fez, antigamente, a terra/ que há neste mundo, o mar nele contido/ o céu, o sol, a lua, as estrelas/ o dia, a noite, o vento e todas as coisas?"

${ }^{6}$ Tupi: "Deus Nosso Senhor."

${ }^{7}$ Tupi: "P. Para quem Deus fez todas as coisas?"

${ }^{8}$ Latim: "Para quem?"

${ }^{9}$ Tupi: "R. Para nós, para [ser] nossa caça, outros para ser nossa criação, outros para ser nossa comida. Com os peixes também a mesma coisa: o sol para nos dar o dia: a lua, para iluminar de noite: e assim mesmo [com] todas as coisas, [por] Deus feitas para nosso uso apenas"
} 
3. P.Cöŷr: mbäeráma Tupána jandé monháng?

Míra mbäérama cecó có ybý pupé? omoçaräimbäeráma? ombaeuuaráma?

Ocäumbaeráma? Oporomonhangmbae-ráma, ? oporomenombaerama? ${ }^{11}$

3. [R.] Aananangaité, aanaangaite. R. Tupána pemonháng /: pejeapuçaca catú :/ Tupaná pemonháng, có ybŷ pupé pecuaûmbaeráma Tupána, i-nhëénga /: i-angaturameté mbäé :/ peporucar- mbäeráma,pemanó riré, ybákypé ${ }^{13}$

\section{[Fl. 2]}

pecetametébäé [peretametébäé], Tupána pe Monhangárapŷri peçóbaeráma, ybáka torýba monhánga nhénhé. ${ }^{14}$

Coŷr ybŷpe peicó, nitiú ybŷpóramo aujeramanhé; goataçáranho peicó. Perapé cycába ybakype cecoû. ${ }^{15}$
Homines ad quid sunt in hâc terrâ? ad ludendum? ad comedendum? ad bibendum? ad se propagan-dos? ad fornicandum? ${ }^{12}$

R. vos fecit /: auscultate ${ }^{16}$ ut sciatis Deum ${ }^{17}$, /: quæ est sanctissma $: /^{18}$

[Fl. 2]

quæ est patria vestra ${ }^{19}$, ad coleste.

gaudium faciendum sine fine ${ }^{20}$.

Nunc in terra estis, non tanquam terræ incolæ pro semper; peregrini solum estis. viævestræterminus in cœloest ${ }^{21}$.

4. P.Nitíu cerá Tupána monháng amó abá, anhánga ratá pé oçóbaeráma? ${ }^{22}$

\footnotetext{
${ }^{10}$ Latim: "Os animais, alguns para criá-los, outros para os comermos; a mesma coisa para os peixes; o sol, para nos dar o dia; a lua para que brilhe quando faz noite; a mesma coisa, enfim, para todo o restante, que Deus fez para o nosso uso."

${ }^{11}$ Tupi: "P. Agora, para que Deus nos fez? As pessoas estão nesta terra para que? Para se divertir? Para comer? Para beber? Para procriar? Para fornicar?"

${ }^{12}$ Latim: "Os homens para que estão neste mundo? Para brincar? Para comer? Para beber? Para procriar? Para fornicar?"

${ }^{13}$ Tupi: "[R.] Não, não. R. Deus vos fez /: escutai bem:/ Deus vos fez, para que nesta terra, Vós conheçais a Deus, a sua lei [palavras] /: que é santíssima:/ para vós a obedecerdes , depois de morrer, para o céu"

${ }^{14}$ Tupi: "qual é a vossa pátria, Deus através de vossa criação apenas para irdes à alegria celestial sem fim."

${ }^{15}$ Tupi: "Agora estais na terra, não como habitantes da terra para sempre; vós sois apenas peregrinos. $\mathrm{O}$ fim do vosso caminho é no céu"

${ }^{16}$ Latim: "[Ele] vos criou /: escutai"

${ }^{17}$ Latim: "para que conheçais Deus"

${ }^{18}$ Latim: "qual é a santíssima [lei]"

${ }^{19}$ Latim: "Qual é a vossa pátria,"

${ }^{20}$ Latim: "Para que tivésseis o gozo do céu sem fim"

${ }^{21}$ Latim: "Agora estais neste mundo, não como moradores da terra para sempre; mas sois somente peregrinos. O ponto final do vosso caminho está no céu."

${ }^{22}$ Tupi: "P. Não será que Deus fez algumas pessoas para irem para o fogo do inferno?"
} 
4. R. Aipobaeráma Tupána nitiú abá monháng? ? $^{23}$

5. P.Maranamótepe abá canhem etéu ${ }^{25}$

5. R. Tupána nhëénga rupí cecoeŷma recé. $^{27}$

6. P.Umabaepé icó ára póra pabé çüí ixoûne ybakypé? ${ }^{29}$

6 R. Christaõ eté anhó. ${ }^{31}$

7. P.Abá cupépe[çupé], Christaõ acẽ[acé]iëú? ?3 $^{33}$

7. R.Imongaraibipŷra, Jesu Christo rerobiaçára, i-nhëénga mombegoârabé ${ }^{35}$

[Fl. 2v]
R. Ad hoc Deus ne-

-minem creavit. ${ }^{24}$

Pois porque se danaõ tantos? ${ }^{26}$

R. quia non servant legem $\mathrm{Dei}^{28}$.
Qui ex omnibus hujus mundi incolis sunt salvandi? ${ }^{30}$

R. Solùm veri Chistiani ${ }^{32}$

\section{Quos vocamus Chistianos? $?^{34}$}

R.Baptizatos, in Jesum CHRISTUM. credentes, et ejus legem servantes ${ }^{36}$.

[Fl. 2v]

\section{P.Abatäé Jesu Christo? ${ }^{37}$}

8 R.Tupána Raýreté, apŷabetéabé, jandé jabé, onhemonhangbaepoera ${ }^{38}$

R. Verus Dei Filius ${ }^{39}$,

\footnotetext{
${ }^{23}$ Tupi: "R. Para isso Deus não criou ninguém."
}

${ }^{24}$ Latim: "Para isso Deus não criou ninguém"

${ }^{25}$ Tupi: "P. Então por que as pessoas se perdem muito?"

${ }^{26}$ Interferências do português.

${ }^{27}$ Tupi: "R. Porque não obedecem à lei de Deus."

${ }^{28}$ Latim: "Porque não guardam a lei de Deus."

${ }^{29}$ Tupi: "P. Quais dentre todos os habitantes da terra irão para o céu?"

${ }^{30}$ Latim: "Quem dentre os habitantes desta terra terão que salvar-se?"

${ }^{31}$ Tupi: "R. Só os verdadeiros cristãos."

${ }^{32}$ Latim: "Só os verdadeiros cristãos"

${ }^{33}$ Tupi: "P. A quem chamamos Cristãos?"

${ }^{34}$ Latim: "Quem chamamos de cristãos?"

${ }^{35}$ Tupi: "R. Àqueles que são batizados, creem em Jesus Cristo, e são seguidores de sua lei"

${ }^{36}$ Latim: "Os batizados que creem em Jesus Cristo e que guardam sua lei."

${ }^{37}$ Tupi: "P. Quem é Jesus Cristo?"

${ }^{38}$ Tupi: "R. Filho verdadeiro de Deus e homem verdadeiro, como nós, que se fez [assim]." 
9. P. Jandé J.J.C ${ }^{\circ}$ [Jara Jesus Christo], çüipé Christaõ oguerama ráricerã $?^{40}$

9. R. Ixüí tári. ${ }^{42}$

10. P.Christaõpé ndé. ${ }^{44}$

10 R. Christaõ xé, Tupána graça recé. ${ }^{46}$

11. P.Maranamopé Christaõ xé Tupána gráça recé eré? ${ }^{48}$

11 R. Nã xé recócatúagoera, coipó xe Rúba, coipó xe Máya, coipó amómbäé Tupána remimonhangoéra é recéruã. Chistaõ xé Tupána angaturáma, Tupána porauçubára recé, J.J.J.C ${ }^{\circ}$. reõagoera, i-poraraçagoera recebé. ${ }^{50}$

12. P.Majauetäé Tupána abá rerecó, Chistaõ onhemonhángrame. ${ }^{52}$
Christiani à Jesu Christo sumpserunt suum nomen ${ }^{41}$

R. Ab illo sumpserunt. ${ }^{43}$

Esné Christianus ${ }^{45}$

R. Sum per Dei gratiam ${ }^{47}$

Cur dices $\mathrm{p}$ [per] Dei graám [gratiam] ${ }^{49}$

R. porque non per mea merita, nec patris mei, aut matris meæ aut alterius creatura Sum Christianus per Dei bonitatem, et mysericordiam ${ }^{51}$

${ }^{39}$ Latim: "O verdadeiro Filho de Deus"

${ }^{40}$ Tupi: "P. De Nosso Senhor Jesus Cristo por ventura os cristãos tomaram o nome?"

${ }^{41}$ Latim: "Os cristãos tomaram seu nome de Jesus Cristo?"

${ }^{42}$ Tupi: "R. Dele o tomaram."

${ }^{43}$ Latim: "O tomaram dele"

${ }^{44}$ Tupi: "P. És cristão?"

${ }^{45}$ Latim: "Tu és cristão?"

${ }^{46}$ Tupi: "Sou cristão, pela graça de Deus"

${ }^{47}$ Latim: "Sou, pela graça de Deus"

${ }^{48}$ Tupi: "Por que dizes sou cristão pela graça de Deus?"

${ }^{49}$ Latim: "Porque dizes por graça de Deus?"

${ }^{50}$ Tupi: "R. Não porque vivi honestamente, ou por meu Pai, ou pela minha Mãe, ou por qualquer outra coisa que Deus tenha feito. Sou cristão pela bondade de Deus, pela misericórdia de Deus Nosso Senhor Jesus Cristo, pela sua morte e pelos seus sofrimentos."

${ }^{51}$ Latim: "Porque não por meus merecimentos, nem [os] de meu pai, nem de minha mãe, ou de outra criatura. Sou cristão pela bondade e misericórdia de Deus."

${ }^{52}$ Tupi: "P. De que modo trata Deus aquele que se faz cristão?"

${ }^{53}$ Latim: "Como é que Deus trata aquele que se fez cristão?"

130 Monserrat, Barros, Arenz \& Prudente. O sinal da Cruz em um catecismo na língua... 120-141. 


\section{[Fl.3]}

12 R. Tupána Taýraráma, omoingou, ybâka poraráma omoingou: ${ }^{54}$

13 P.Abá nitiú onhemonhangpotárame-Christaõ, marãtäé? ${ }^{56}$

13. R. Juriparí remiauçubarama opŷtá. ${ }^{58}$

14. P.Eremombëú üã ixebo abá reroki-pŷra réra, coŷr emombeú ixebo: mbäétäé Christaõ jecua-pába. ${ }^{60}$

14 R. Santa cruz räangába ${ }^{62}$.

15. P.Mbäé recé? ${ }^{63}$

15. R. I-aribó J.J.J.C [Jesus Cristo] omanó recé, jandé pycyrõbaeráma recé erimbäé. ${ }^{64}$

16. P.Mobýr tecó rupí Christaõ monháng Santa cruz $^{66}$.
[Fl.3]

R. Dei Filium illum constituit, cœlestem civem illum constituit. ${ }^{55}$
Qui non vult se facere

Cristianum, quid illo fit? ${ }^{57}$

R.Diaboli mancipium manet ${ }^{59}$.

Dixisti mihi jam hominis bap-tizati nomen, nunc dic mihi: quodnam Xtni [Christiani] sig-num? $?^{61}$
R. q [quæ] super illâ N.D.J.C. mortuus est olim, ut redimeret. ${ }^{65}$

\footnotetext{
${ }^{54}$ Tupi: "R. Ele o torna filho de Deus, torna-o habitante do céu."

${ }^{55}$ Latim: "O constitui Filho de Deus, o constitui cidadão do céu"

${ }^{56}$ Tupi: "P. Àquele que não quer se fazer cristão, o que acontece?"

${ }^{57}$ Latim: "Àquele que não quer se tornar cristão, o que lhe acontece?"

${ }^{58}$ Tupi: "R. Fica escravo do diabo."

${ }^{59}$ Latim: "Permanece escravo do diabo"

${ }^{60}$ Tupi: "P. Tu já me disseste quem é o batizado [aquele a quem foi tirado o nome], agora me diz: qual é o sinal do Cristão."

${ }^{61}$ Latim: "Já me disseste o nome do homem batizado/ agora diga-me: qual é o sinal do cristão?"

${ }^{62}$ Tupi: "R. O sinal da Santa Cruz."

${ }^{63}$ Tupi: "P. Por que?"

${ }^{64}$ Tupi: "R. Porque em cima dela N.S.J.C. morreu, para nos redimir, outrora."

${ }^{65}$ Latim: "Aquela sobre a qual N.S.J.C. foi morto uma vez, para nos redimir/"

131 Monserrat, Barros, Arenz \& Prudente. O sinal da Cruz em um catecismo na língua... 120-141.
} 
16 R. Mocoĩ rupí ${ }^{68}$.

17. P.Marã eitäé? ${ }^{69}$

[Fl. 3v]

17 R. Jandé recé Christaõ jecuapába

jandé moína, jandé nhemongaribabé ${ }^{71}$

18 P. Marã jabépe acẽCristaõ jecuapaba oioecé imöíni.

18 R. Opó acatuaba [ecatuaba] acẽçokendápa, opópöagoaçú mopöámabé, cruz mirí moçapýr, ojepé ocybápe, amo ojurúpe, amó opotiápe imonhánga coyté ${ }^{75}$

19. P.Mbäétäé ëipé acẽ emonã, oçobaçápa? ${ }^{77}$

19 R. Ocybápe acẽ cruz möína, $\underline{\text { Santa }}$

cruz raangaba recé, ëí: äēriré acẽ

ojurúpe amó möína, orépŷcŷrõ jepé

Tupána ore Jara, ëí : äé riré abé amó opotiápe acẽ möína, oré amotareŷmbara çüí, ëí. $^{79}$
R.

Quales sunt $^{70}$

$$
\text { [Fl. 3v] }
$$

R. In hoc Xtnorum [Christianorum] signum ponendo, et nos benedicendo. ${ }^{72}$

Quomodo nós sig-

-namus? ${ }^{74}$

R. Fechando a maõ direita, et pollice faciendo cruces parvas tres, unam in fronte, aliam in ore, aliam in pectore ${ }^{76}$.

Quid dicimus, nos signando ${ }^{78}$

R.Faciendo unam in fronte crucem, per Signum Sanctæ crucis dicimus: postea in ore aliam faciendo, libera nos

Deus noster! dicimus: postea aliam in pectore faciendo, ab inimicis nostris

${ }^{66}$ Tupi: "P. De quantas maneiras o Cristão faz a Santa Cruz?"

${ }^{67}$ Latim: "De quantos modos?"

${ }^{68}$ Tupi: "De duas maneiras."

${ }^{69}$ Tupi: "Como se diz?"

${ }^{70}$ Latim: "Quais são [estes modos]?"

${ }^{71}$ Tupi: "R. Em nós o sinal do Cristão nos pondo, e os benzendo."

${ }^{72}$ Latim: "Fazendo este sinal do cristão e nos bendizendo"

${ }^{73}$ Tupi: "P. De que outro modo a pessoa põe em si mesma o sinal do Cristão? [Como nos persignamos?]"

${ }^{74}$ Latim: "De que modo nos persignamos?"

${ }^{75}$ Tupi: "Fechando a mão direita, erguendo o polegar, fazendo três pequenas cruzes, uma na testa, outra na boca e, finalmente, outra no peito."

${ }^{76}$ Latim: "Fechando a mão direita e com o polegar fazendo três pequenas cruzes, uma na testa, outra na boca, outra no peito"

${ }^{77}$ Tupi: "P. O que dizemos então, ao nos persignar?"

${ }^{78}$ Latim: "De que modo nos persignamos?"

132 Monserrat, Barros, Arenz \& Prudente. O sinal da Cruz em um catecismo na língua... 120-141. 
dicimus. ${ }^{80}$

20. P.Maranamopé acẽ öcybápe jabaçába [jobaçába] möíni? ${ }^{81}$

20 R.Taxepŷcŷrõ Tupána maenduaçàba äíba çuíi. ${ }^{83}$

21. P.Maranamopé acẽ ojurúpe çaanghino $?^{85}$

[Fl. 4]

21 R.Toipëá Tupána nhëénga memoã xé jurú çüí. ${ }^{87}$

22. P.Maranamopé acẽ opotiápe imöini? ${ }^{89}$

22 R.Taxepëá Tupána tecoángaipába çuií, acẽ nhia cüí [çuí ] océmbäé. ${ }^{91}$
Cur facimus signum crucis in fronte ${ }^{82}$

\section{R. Ut me Deus liberet cogitationibus malis $^{84}$}

Cur in ore ${ }^{86}$

[Fl. 4]

R. Ut segreget Deus verba mala ab ore meo. ${ }^{88}$

Cur in pectore $?^{90}$

R. Ut me segreget Deus âb operibus malis, è corde nostro, que prodeunt. ${ }^{92}$

\footnotetext{
${ }^{79}$ Tupi: "R. Pondo a cruz na testa, Pelo sinal da Santa Cruz dizemos; depois nos pondo outra na boca, dizemos livrai-nos Deus Nosso Senhor; e depois nos colocando outra no peito, dizemos, dos nossos inimigos."

${ }^{80}$ Latim: "Ao fazer uma cruz na testa dizemos pelo sinal da Santa Cruz, e depois fazendo outro na boca dizemos livrai-nos nosso Deus; depois fazendo outro no peito dizemos dos nossos inimigos"

${ }^{81}$ Tupi: "P. Por que nos colocamos a cruz na testa?"

${ }^{82}$ Latim: "Porque fazemos o sinal da cruz na testa?"

${ }^{83}$ Tupi: "R. Que Deus me livre das tentações [das más lembranças, dos maus pensamentos]"

${ }^{84}$ Latim: "Para que Deus nos livre dos maus pensamentos"

${ }^{85}$ Tupi: "P. Por que a sinalizamos na boca?"

${ }^{86}$ Latim: "Para que na boca?"

${ }^{87}$ Tupi: "R. Que Deus afaste as más palavras da minha boca."

${ }^{88}$ Latim: "Para que Deus impeça palavras más em minha boca."

${ }^{89}$ Tupi: "P. Por que a colocamos no peito?"

${ }^{90}$ Latim: "Para que no peito?"

${ }^{91}$ Tupi: "R. Que Deus me afaste do pecado [maldade], que sai do nosso coração."

${ }^{92}$ Latim: "Para que Deus me afaste das más obras que procedem do nosso coração." 
23. P.Marã jabépé acẽ nhemongaräibi?

Majauetäé abá

Christaõ

jecuapãba onóng? ${ }^{93}$

23. R. Ocekendá ipó ecatuába, ipópoa-goaçúnhó mopoáma, i-pupé moçapýr cruza mirí monháng, ojepé ocybápe, ojurupé amó, opotiápe amó coyté. ${ }^{96}[$ Trecho rasurado]

24. P.Marã ëí abá, aipó moçapýr cruza mirí monhánga? ${ }^{98}$ [Trecho rasurado]

24. R. Ocybápe cruza monhángrame, Santa cruz

räangába recé, ëí: ojurúpe amo o-moinrame,orepy ${ }^{100}$ [Trecho rasurado]

R. Ocekendabóc abá opó ecatuába,ipupé oçaýr cruz ocybá çüí1 ${ }^{101}$

$[\mathrm{Fl} .4 \mathrm{v}]$

athe ocuá rupí catú ranhé, äé riré oatiŷba açúra çüí oatiŷba ecatuaba cotý cruza mombab. ${ }^{102}$
Quomodo $^{94}$

Quomodo aliquis in se Xtnórum [Christianorum] signum facit? ${ }^{95}$

R. Claudit suam manum dextram, suum pollicem solum erigendo, illo tres cruces parvas facit, unam in sua fronte, in suo ore aliam, in suo pectore aliam deniq[ue]..$^{97}$ TTrecho rasurado]

Quomodo dicit aliquis, has tres cruces parvas faciendo? ${ }^{99}$ [Trecho rasurado]
R. Aperit quis suam manum dexteram, illâ delineat crucem à sua fronte, ${ }^{103}$

$[\mathrm{Fl} .4 \mathrm{v}]$

bene usq[ue] ad medium sui corporis inprimis, postea à suo humero sinistro, suum hume [rum] dextrum versus crucem absolvit. ${ }^{104}$

\footnotetext{
${ }^{93}$ Tupi: "P. Como ainda nós nos benzemos? De que outro modo a pessoa faz o sinal do Cristão?"

${ }^{94}$ Latim: "De que modo?"

${ }^{95}$ Latim: "De que modo alguém faz em si o sinal dos cristãos?"

${ }^{96}$ Tupi: "R. Fecha sua mão direita, erguendo só o seu polegar, com ele três cruzes pequenas faz, uma na sua testa, na sua boca outra, no seu peito outra finalmente."

${ }^{97}$ Latim: "Fecha sua mão direita, somente elevando seu polegar e com ele faz três pequenas cruzes, uma em sua testa, outra na sua boca e enfim outra em seu peito."

${ }^{98}$ Tupi: "P. O que diz a pessoa, fazendo estas três cruzes pequenas?"

${ }^{99}$ Latim: "Como é que alguém diz ao fazer estas três pequenas cruzes?"

${ }^{100}$ Tupi: "R. Ao fazer a cruz na sua testa, diz Pelo sinal da Santa Cruz; quando faz outra no seu peito, [vocábulo incompleto]"

${ }^{101}$ Tupi: "R. A pessoa abre sua mão direita, com ela risca uma cruz desde sua testa."

${ }^{102}$ Tupi: "até bem a sua cintura primeiro, e depois do seu ombro esquerdo, em direção ao seu ombro direito uma cruz faz."

${ }^{103}$ Latim: "A pessoa abre sua mão direita, com ela traça uma cruz a partir de sua testa."

134 Monserrat, Barros, Arenz \& Prudente. O sinal da Cruz em um catecismo na língua... 120-141.
} 
25.P.Marã ëítäé abá, jabé onhemonga-raiba? ${ }^{105}$

25 R. Abá onóngrame opó ocŷbápe, Túba, ëí: ocýcrame ipó icuape,

Taýra, ëí: äé riré ocykyrame ipó oatiŷba açura çüí oatîyba ecatuába cotý, Espirito.Santo.rera pupé ëí : ${ }^{107}$

26. P.Mbäé recé abá jobaçáb? ${ }^{109}$

26 R. Santissma. Trindade Túba,Taýra

Espirito Santo moçapýr abá, ojepenhó

Tupána mombëuráma recé. ${ }^{111}$

27. P.Mbäe recébe abá jobaçábi? ${ }^{113}$

27 R. Oremombeurama recebé, Tupá Taýra ybâkaçuí oúragoéra, $S^{a}$ MARIA cunhã mbucú [mbuçú] i-jabykyéyma mnhe [nhenhé]barriga pupé, apŷabeté onhemonhángagöéra, ${ }^{115}$

[Fl. 5]
Quomodo dicit aliquis, sic se benedi-cendo? ${ }^{106}$

Cūm quis ponit manum suam in suâ fronte dicit:...cūm p[er]tingit illius manus ad mediū sui oris

dicit:........Dein cūm traxerit manum suam ab humero suo sinistro, humerum suū dextrū versùs, dicit...... ${ }^{108}$

Quare homo se benedicit? ${ }^{110}$

R. Ad profitendum, ${ }^{112}$

Cur ampliùs $?^{114}$

R. Ut profiteamur insuper Dei Filium de cœlo venisse, in Santa MARIA Semper virginis intemérata ventre hominem factum ${ }^{117}$,

\footnotetext{
${ }^{104}$ Latim: "Em primeiro lugar, bem até ao meio de seu corpo, depois de seu ombro esquerdo a seu ombro direito, [assim] faz-se a cruz."

${ }^{105}$ Tupi: "P. O que diz a pessoa também ao se benzer?"

${ }^{106}$ Latim: "Como é que alguém fala se benzendo assim?"

${ }^{107}$ Tupi: "R. A pessoa, quando põe sua mão na testa, diz [do] Paí; quando chega sua mão no meio da cintura diz [do] Filho; e, então, quando chega sua mão do ombro esquerdo em direção ao ombro direito, [do] Espirito Santo em nome, se diz."

${ }^{108}$ Latim: "Quando a pessoa põe sua mão na sua testa, diz: ... Quando a mão dele chega no meio de sua boca, diz: ... Em seguida, quando sua mão traçar de seu ombro esquerdo para seu ombro direito, diz: ..."

${ }^{109}$ Tupi: "P. Por que as pessoas se persignam?"

${ }^{110}$ Latim: "Por que razão a pessoa se benze."

${ }^{111}$ Tupi: "R. Para professar [que] a Santíssima Trindade, Pai, Filho, Espirito Santo são três pessoas e um só Deus."

${ }^{112}$ Latim: "Para professar [a fé]"

${ }^{113}$ Tupi: "P. Por que mais as pessoas se persignam?"

${ }^{114}$ Latim: "Para que mais?"

${ }^{115}$ Tupi: "R. Para declarar [que] Deus Filho veio outrora do céu, S ${ }^{\text {a }}$ MARIA jovem não trabalhada na barriga, homem verdadeiro se fez outrora,"
}

135 Monserrat, Barros, Arenz \& Prudente. O sinal da Cruz em um catecismo na língua... 120-141. 
cruza áribo omanóbaepöéra, oaçúra.

/:jandé canhemagöéra mombeuçába :/

çüí, oecatuába /: ybâkypé jande co-

-rama [çorama] mombegoãba:/ cotý, jande

reraçóagöéra mombëuráma nhenhe ${ }^{116}$.

28 P.Mbäé recebé? ${ }^{119}$

28 R. Anhánga mondyjaráma recé, mbäeaäíbá pabé, jandé robaké çuií momocembäeráma. ${ }^{120}$

29. P. Majauerámetäé corí jandé jobaçáb? ${ }^{122}$

29 R. Mbäé ypŷrúnga jabiõ pupé, coipo máme maranmarán jaicobaeráma recé, jacykyjeráme. $^{123}$

30. P.Majauérameabé? ${ }^{125}$

30 R. Ore pacárame, okaçuií orecém rame, Tupã ókype oreikérame,oré kéra janondébé. $^{127}$

31. P.Ocobacábtäé [oçobaçabtäé] abá cembiurama. $^{129}$ in cruce mortuum fuisse, à sinistrâ suâ /: nostræ perditionis significativâ :/ dexteram suam /: salvationis nostræ fu-tura significativâ :/ versùs nos transtu-lisse ad profitendum constanter. ${ }^{118}$

R. Ad dæmonem intimitandū, malum omne ex nostra præsentia ad pellendum. ${ }^{121}$

\section{Quando}

R. In rei cujusvis principio, aut alicubi aliquid adversi nos passuros, ubi timuerimus. ${ }^{124}$

Et quando magis? ${ }^{126}$

R. Cum evigilamus, domo eximus, Ecclesiam intramus, et ante somnum nostrum. ${ }^{128}$

Benedicúntne hocs [hos]cibos suos? ${ }^{130}$

\footnotetext{
${ }^{117}$ Latim: "Para que professemos, acima de tudo, que o Filho de Deus/ veio do céu por SANTA MARIA/ no ventre da Virgem, sempre intemerata,/ se fez homem/"

${ }^{116}$ Tupi: "em cima da cruz morreu, da sua esquerda, /: [que] declara nossa perdição:/ em direção à sua direita /: [que] declara nossa ida para o céu [salvação] :/, nos leva a declarar [isso] constantemente."

${ }^{118}$ Latim: "que foi morto na cruz, da sua esquerda/ significando a nossa perdição:/ a sua direita /significando a nossa futura salvação; que transferiu a nós/ para professarmos constantemente"

${ }^{119}$ Tupi: "P. E por que mais?"

${ }^{120}$ Tupi: "R. Para assustar o demonio, para todas as coisas ruins da nossa frente fazer sair."

${ }^{121}$ Latim: "Para intimar o demônio, para expulsar todo mal da nossa presença."

${ }^{122}$ Tupi: "P. Quando ainda nos persignamos?"

${ }^{123}$ Tupi: "R. No início de qualquer coisa, ou quando estamos bem mal, quando estamos com medo."

${ }^{124}$ Latim: "No começo de qualquer coisa ou em qualquer lugar, [onde] sofreremos alguma adversidade, onde estivermos com medo"

${ }^{125}$ Tupi: "P. E quando mais?"

${ }^{126}$ Latim: " E quando mais?"

${ }^{127}$ Tupi: "R. Quando despertamos, quando saímos de casa, quando entramos na igreja, antes de dormir."

${ }^{128}$ Latim: "Quando acordamos, saímos de casa, quando entramos na igreja e antes de nosso sono." 
31. R.Ocobacáb [oçobaçab], nitiu jandé momarãbäeráma jandé rembiú. ${ }^{131}$

32. P.Mbäérecétäé abá jobaçáb mbäé ypý-rúnga jabiõ pupé? ${ }^{133}$

32 R. Tonhemonháng jandé morabýkyçába, Tupã möetábäerama recé. ${ }^{135}$

33. P.Catútäé abá, cetaŷí oçobaçáb ${ }^{137}$

33 R. Catúeté; Tupã jandé pycyrõbaerama jandé ánga amotareŷmbáreta çüí, umã umã rupí jaicórame ? $^{139}$

34. P.Mbäé pupé täé, orejepŷcŷrõ juripari çüí, ybakypé jaçocatubaerama ${ }^{141}$.

34 R. Tupã rerobiá pupé; Tupã jerobiá pupé; Tupã rauçúba pupé; onhemonga-rípa [-raípa] pupé; Tupã nhëenga rupí, jaicó pupé; tecó morangatú monhánga pupé,

Santa Madre Igreja nhëénga rupí jaicó pupébé, tecoangäipába monhánga
$\mathrm{R}$. Benedicunt, ne nobis noceant cibi nostri ${ }^{132}$

[Fl.6]

Cur ab initio cujusvis rei? ${ }^{134}$

R. ut fiat noster labor

ad Dei honorem ${ }^{136}$

bene agit, qui sæpiús se benedicit? ${ }^{138}$

R. Optimè, ut Deus nos liberet animæ nostræ inimicis, ubi-

cunq[ue]extiterimus ${ }^{140}$.

Quâ nos re liberamus, à dæmone, ut ad colum pertingamus? ${ }^{142}$

R. Fide in Deum, Spe, Amore Dei, procuratione Baptismi, bonos observatione legis Dei, bonorum operum operatione,

Sancta Matris Ecclesia legum observa -tione, peccati commissionem

\footnotetext{
${ }^{129}$ Tupi: "P. As pessoas benzem a comida?"

${ }^{130}$ Latim: "Eles benzem esses seus alimentos?"

${ }^{131}$ Tupi: "R. Nós nos benzemos [persignamos], para que não nos faça mal nossa comida."

${ }^{132}$ Latim: "Benzem para que nossos alimentos não nos façam mal."

${ }^{133}$ Tupi: "P. Por que as pessoas benzem antes de começar qualquer coisa?"

${ }^{134}$ Latim: " Por que no início de qualquer coisa?"

${ }^{135}$ Tupi: "R. Que se faça o nosso trabalho para a honra de Deus."

${ }^{136}$ Latim: "Para que nosso trabalho seja feito para a honra de Deus."

${ }^{137}$ Tupi: "P. É bom que a gente se benza muitas vezes?"

${ }^{138}$ Latim: "Age bem quem se abençoa muitas vezes?"

${ }^{139}$ Tupi: "R. Muito bom; para que Deus livre nossa alma dos nossos inimigos, em qualquer lugar em que estivermos."

${ }^{140}$ Latim: "Muito bem, para que Deus nos livre dos inimigos nossa alma, em qualquer lugar no qual estejamos."

${ }^{141}$ Tupi: "P. Com que nos livramos do demônio, para irmos seguramente para o céu?"

${ }^{142}$ Latim: "Por meio de que nos libertamos do Demônio para que alcancemos o céu?" 
çüí jacykycéetéramebe. ${ }^{143}$

35. P.Mbäé pupébetäé orejepycyrõgatú anhánga cüí [çuí] ${ }^{145}$

\section{[Fl. 6]}

35 R. Santa Madre Igreja Sacramentos raçaba pupé, nhemombëúcatú pupé, Tupã raçaba pupé, Tupána graça pupé oicó pupé ${ }^{147}$.

36. P.Onhemoçainan catútäé Christaõ, aipó pabé ybâkype ceraçoçabeta pupé ${ }^{149}$

36 R. Onhemoçainan eté cecé ${ }^{151}$. ubi summè timuerimus ${ }^{144}$.

Quibus porrò mediisnos perquamliberamus à dæmone? ${ }^{146}$

$$
\text { [Fl. 6] }
$$

R. Sanctæ Matris Ecclesiæ Sacramentorū susceptione, confesssione bonâ, communione,in Dei Gratia perseverantiâ. $^{148}$

Debetne procurare omni studio Xtnús [Christianus], hæc omnia ad cœlum quæ ipsum perducunt ${ }^{150}$

R. Omni studio. ${ }^{152}$

\section{Agradecimentos}

Agradecemos ao Programa de Capacitação Institucional (PCI) do Ministério da Ciência e Tecnologia (MCT - Brasil) que possibilitou o deslocamento da primeira autora para o Museu Paraense Emílio Goeldi (MPEG - Brasil) onde foram realizadas pesquisas e discussões pertinentes para a realização deste trabalho. Ao Conselho Nacional de Desenvolvimento Científico e Tecnológico (CNPq) pelo apoio e financiamento concedido para a segunda autora. À Evahir Pereira pela a transcrição paleográfica preliminar; ao Padre Ilario Govoni pela tradução do latim.

\footnotetext{
${ }^{143}$ Tupi: "R. Crendo em Deus; confiando em Deus; amando a Deus; fazendo-se batizar; seguindo a lei de Deus; levando uma vida santa; seguindo os mandamentos da Santa Madre Igreja, de pecados fazer tendo muito medo também [e tendo muito medo de fazer pecados]"

${ }^{144}$ Latim: "Pela fé em Deus, pela esperança, pelo amor de Deus, pela administração do Batismo, pela observância da lei de Deus, pela execução de boas obras, pela observância dos mandamentos da Santa Madre Igreja, [alcançando] a remissão do pecado lá onde mais [o] temeremos."

${ }^{145}$ Tupi: "P. Por que outros meios nos livramos bem do demônio?"

${ }^{146}$ Latim: "Com que meios mais nos libertamos enfim do Demônio?"

${ }^{147}$ Tupi: R. Por meio dos Sacramentos da Santa Madre Igreja, pela confissão, pela comunhão, na graça de Deus vivendo."

${ }^{148}$ Latim: "Pela recepção dos sacramentos da Santa Madre Igreja, por uma boa confissão, pela comunhão, pela permanência na graça de Deus."

${ }^{149}$ Tupi: "P. O Cristão deve ocupar-se muito com todos aqueles que foram levados para o céu?"

${ }^{150}$ Latim: "O cristão deve procurar com todo esforço tudo isso que nos conduz ao próprio céu?"

${ }^{151}$ Tupi: [Devem] ocupar-se muito com isso.

${ }^{152}$ Latim: "Com todo esforço."

138 Monserrat, Barros, Arenz \& Prudente. O sinal da Cruz em um catecismo na língua... 120-141.
} 


\section{Referências bibliográficas}

Anchieta, J. de (1595). Arte da grammatica da lingoa mais usada na costa do Brasil. Coimbra, Portugal: Antonio de Mariz.

Anônimo (175- a). Doutrina christaã em lingoa geral dos Indios do Estado do Brasil e Maranhaõ, composta pelo P. Philippe Bettendorff, traduzida em lingoa geral e irregular, e vulgar uzada nesses tempos. Biblioteca da Universidade de Coimbra, ms.1089.

Anônimo (175- b). "Prosodia da lingoa" [dos Indios]. In:ANÔNIMO. Dicionario da lingua falada por indios do Brasil, contendo no fim vários textos principalmente os anteriores escritos na mesma lingua. Academia das ciências de Lisboa, ms., cota, MA no. 569.

Anônimo (175- c).Vocabulario da lingua Brazil. Biblioteca Nacional de Portugal, Códice 3143.

Anônimo (1756). [Dicionário Português-Língua Geral e Língua Geral-Português]. Stadtbibliothek / Stadtarchiv Trier, Alemanha, ms. 1136/2048 $4^{\circ}$.

Araújo, A. de (1618). Catecismo na Lingoa Brasilica, no qual se contem a summa da doctrina christã. Com tudo o que pertence aos Mysterios de nossa sancta Fè \& bõs custumes. Composto a modo de Dialogos por Padres Doctos, \& bons lingoas da Companhia de IESUS. Agora novamente concertado, ordenado, \& acrescentado pello Padre Antonio d'Araujo Theologo, \&lingoa da mesma Companhia. Lisboa, Portugal: Pedro Crasbeeck.

Araújo, A. de \& Leam, B. de (1686). Catecismo brasilico da doutrina christaã, com o ceremonial dos sacramentos, \& mais actos parochiaes. Composto por padres doutos da Companhia de Jesus, aperfeiçoado, e dado a luz pelo Padre Antonio de Araújo da mesma companhia. Emendado nesta segunda impressão Pelo Bertholameu de Leam da mesma companhia. Lisboa, Portugal: Officina Miguel Deslandes.

Barros, C.\& Monserrat, R. (2012). Notas sobre um catecismo manuscrito na língua geral "vulgar" da Amazônia (século XVIII). In: C. A.Lagorio, M. C. Rosa, J. R. B. Freire (Ed.),Política de línguas no Novo Mundo(pp. 127-148). Rio de Janeiro, Brasil: EDUERJ.

Barros, C. \& Monserrat, R. (2015). Fontes manuscritas sobre a Língua Geral da Amazônia escritas por jesuítas "tapuitinga" (século XVIII). Confluência, Rio de Janeiro, Brasil, n. 49, p. 236-254.

Barros, C. \& Monserrat, R. (2016). Uma proposta de vernacularização da tradição discursiva jesuítica na língua geral da Amazônia em um catecismo manuscrito no século XVIII. In: S. D.-S. Sáenz. (Ed.), La transmisión de conceptos cristianos a las lenguas amerindias (pp. 269-288). Sankt Augustin, Alemanha: Academia Verlag.

Bettendorff, J. F.(1687). Compêndio da Doutrina Christaã na Língua Portuguesa e Brasílica. Lisboa, Portugal: Imprensa Miguel Deslandes.

Daniel, J. (2004). Tesouro descoberto no máximo rio Amazonas. Volume 2. Rio de Janeiro, Brasil: Contraponto.

139 Monserrat, Barros, Arenz \& Prudente. O sinal da Cruz em um catecismo na língua... 120-141. 
Eckart, A. (1778).Litteratur. 5. Von den Sprachen in Brasilien, Specimen linguae brasilica vulgaris. In: C. G. von Murr (ed.),Journal zur Kunstgeschichte und zurallgemeinen Litteratur, Alemanha, tomo 6, pp. 197-211.

Eckart, A. (1994) O Exemplário da língua corrente do Brasil [1778]. Tradução do latim de Carlos Antônio Kalil Tannus e Miguel Barbosa do Rosário. Terceira Margem-Revista da Faculdade de Letras da Universidade Federal do Rio de Janeiro, Rio de Janeiro, Brasil, v. 2(2),pp. 176-180.

Eckart, A. (2013). Aditamentos do Senhor Pe. Anselm Eckart, Ex-pregador da Companhia de Jesus na Capitania do Pará no Brasil, à "Descrição das Terras do Brasil" de Pedro Cudena e às "Notas à Sexta Contribuição de Lessing para a História e a Literatura, dos Tesouros da Biblioteca Ducal de Wolfenbüttel, Braunschweig, 1781, gr. $8^{\mathrm{o}}$ ” do Senhor Reitor Christian Leiste. In: Papavero, N. \& Porro, Antonio (Ed.), Anselm Eckart, S.J. e o Estado do Grão-Pará e Maranhão (1785). Belém, Brasil: Museu Paraense Emílio Goeldi.

Fay, D. (1942). As cartas do P. David Fay e sua biografia. Tradução do húngaro e do latim por Paulo Ronai. Anais da Biblioteca Nacional, Rio de Janeiro, Brasil vol. LXIV, pp.192-273.

Fernández Arrillaga, I. \& García Arenas, M. (2009). Dos caras de una misma expulsión: el destierro de los jesuítas portugueses y la reclusión de los missioneros alemanes. Hispania Sacra, Madrid, Espanha, LXI, 123, pp. 227-256.

Figueira, L. (1621). Arte da lingua brasilica. Lisboa, Portugal: Manoel da Silva.

Figueira, L. (1687). Arte de grammatica da lingua brasílica. Lisboa: Officina de Miguel Deslandes.

Leite, S. (1949a). História da Companhia de Jesus no Brasil. Tomo VIII. Rio de Janeiro, Brasil: Instituto Nacional do Livro / Lisboa, Portugal: Livraria Portugália.

Leite, S. (1949b). História da Companhia de Jesus no Brasil. Tomo IX. Rio de Janeiro, Brasil: Instituto Nacional do Livro / Lisboa, Portugal: Livraria Portugália.

Mattos, Y. de (2012). Regimento das Missões do Estado do Maranhão e Grão-Pará, de 21 de dezembro de 1686: comentário. 7 Mares - Revista dos pós-graduandos em História Moderna da Universidade Federal Fluminense, Rio de Janeiro, Brasil, n. 1, v. 1, pp. 112-123.

Maxwell, K. (1996). Marquês de Pombal: paradoxo do iluminismo. Tradução de Antônio Pádua Danesi. $2^{\text {a }}$ ed. Rio de Janeiro, Brasil: Paz e Terra.

Meier, J. \& Aymoré, F. A. (2005). Jesuiten aus Zentraleuropa in Portugiesisch- und Spanisch-America. Ein bio-bibliographisches Handbuch. Band 1: Brasilien (1618-1760). Münster, Alemanha: Aschendorff Verlag.

Mendonça, M. C. de (2005). A Amazônia na era pombalina: correspondência do Governador e Capitão-General do Estado do Grão-Pará e Maranhão, Francisco Xavier de Mendonça Furtado: 1751-1759. 2a ed. 3 Tomos. Brasília, Brasil: Senado Federal, Conselho Editorial. 
Monserrat, R., Barros, C. \& Schmidt-Riese, R. (2017). Usos discursivos dos parênteses em um catecismo jesuítico na língua geral da Amazônia ([175-]). Revista de Estudos da Linguagem, Belo Horizonte, Brasil, v. 25, pp. 85-110.

Portugal (1758). Directorio, que se deve observar nas povoaçoens dos indios do Pará, e Maranhão: em quanto Sua Magestade nã̃ mandar o contrario. Lisboa, Portugal: Na Officina de Miguel Rodrigues, Impressor do Eminentíssimo Senhor Cardeal Patriarca.

Prudente, G. C. P. (2017). Entre índios e verbetes: a política linguística na Amazônia portuguesa e a produção de dicionários em língua geral por jesuítas centroeuropeus (1720-1759). 189 f. Dissertação (Mestrado) - Universidade Federal do Pará, Instituto de Filosofia e Ciências Humanas, Belém, Brasil, Programa de Pós-Graduação em História Social da Amazônia.

Rosa, M. C. (1994). Um exemplo de descrição pedagógica no século XVIII: O Specimen linguae brasilicae vulgaris e a tradição jesuítica de ensino de segunda língua. Terceira Margem - Revista da Faculdade de Letras da Universidade Federal do Rio de Janeiro, Rio de Janeiro, v. 2 (2), pp.181-189.

Santos, F. J. dos \& Sampaio, P. M. M. (2008). 1755, ano da virada na Amazônia portuguesa. Somanlu: Revista de Estudos Amazônicos, Manaus, ano 8, n. 2, pp. 79-98.

Wright, J. (2006). Os jesuítas: missões, mitos e histórias. Tradução de André Rocha. Rio de Janeiro: Relume Dumará. 